
3 Research Square
Preprints are preliminary reports that have not undergone peer review.
They should not be considered conclusive, used to inform clinical practice, or referenced by the media as validated information.

\title{
The influence of pH-salt Concentrations on Tuning lower critical solution temperature of Poly(NIPAAm-co-DMAA-co-DTBAVA) Multi-Environmentally terpolymer
}

momen abdelaty ( $\square$ abdelatymomen@yahoo.com)

Al-Azhar University Faculty of Science https://orcid.org/0000-0002-7442-7053

\section{Research Article}

Keywords: Thermal/pH-Salt concentrations environmentally terpolymer, N-isopropylacrylamide, N, N-dimethylacrylamide, Hofmeister anion, LCST/cloud point

Posted Date: March 7th, 2022

DOI: https://doi.org/10.21203/rs.3.rs-1359424/v1

License: @ (i) This work is licensed under a Creative Commons Attribution 4.0 International License. Read Full License 


\section{Abstract}

New series of thermo-pH responsive terpolymers were fabricated. Cationic acrylate tertiary amine monomer based on vanillin was synthesized in two steps and named by [2-((ditert-butylamino)methyl)-4-formyl-6-methoxyphenyl acrylate] and abbreviated as (DTBAVA). ${ }^{1} \mathrm{H}$ NMR, ${ }^{13} \mathrm{C}$ NMR investigated the new compounds, and FT IR exhibited good results. The new terpolymer was fabricated by the free radical polymerization of $N$-isopropylacrylamide NIPAAm, 10 mol\% $N$, $N$-dimethylacrylamide and 5, 10, and 20 mol\% DTBAVA. The investigation process involved the chemical method such as ${ }^{1} \mathrm{H}$ NMR and FT IR; physical methods for the solid terpolymers as glass temperature by DSC, polymer degradation by TGA, and polymer crystallinity via XRD. For terpolymer solution, gel permeation chromatography GPC was performed for molecular weights and dispersity; contact angles for identifying the hydrophilic or hydrophobic terpolymers solutions. The lower critical solution temperatures $T_{c, s}$ and cloud points $C_{p^{\prime} s}$ of terpolymers were recorded considering the impact of pH solutions and the concentrations of different sodium salts of $\left(\mathrm{SO}_{4}{ }^{-2}, \mathrm{Cl}^{-1}\right.$, and $\left.\mathrm{SCN}^{-1}\right)$ kosmotropes to chaotropic in the Hofmeister series; turbidity measurements were used via UV/vis spectroscopy and micro-DSC. In a new optimization study, we will use these terpolymers in the post-polymerization with biomolecules such as chitosan, protein, and amino acids via Schiff base.

\section{Introduction}

To define the environmental polymers, it is a material that can change their behavior according to the surrounding environment. In the last few decades, scientists have revealed several kinds of environmental materials; they are defined with different meanings, such as responsive, intelligent, smart, and stimuliresponsive [1-6]. This material has been rapidly developed according to modern technology and its applications [7-9]. The sensitivity of polymers to temperature is known as thermo-responsive polymeric material [10-12]. According to the phase separation temperature of the polymer solution, there are two significant kinds; first is the most popular and has exhibited separation (two phases) after heating over its transition temperature, and known as lower critical solution temperature or (LCST) [13-15]. On the other hand, the separation process occurred before its separation temperature, one phase after heating, while two phases before heating and defined as upper critical solution temperature (UCST) [16, 17]. The main factor in both behaviors is the hydrogen bonding interaction between polymer chains and water molecules. Increasing the hydrogen bonding interaction raises the separation temperature to higher values and vice versa [13]. Massive studies have focused on preparing LCST copolymers using N-ispropylacrylamide (NIPAAm) [14-23]. The homo-polymerization of NIPAAm (PNIPAAm) shows the LCST at $32{ }^{\circ} \mathrm{C}[13,15]$; moreover, the copolymerization with different monomers with hydrophilic or hydrophobic groups will change LCST significantly to higher or lower value [24-27]. Other significant environmental polymers are pH-sensitive; they can change their behavior in response to the $\mathrm{pH}$ solution [28,29]. They are polyelectrolytes with acidic or basic functional groups that can ionize in acidic or basic solutions [30, 31]; Carboxylic functional polymers such as poly(acrylic acid) PAA is a significant example of anionic polyelectrolyte [32]. Introducing of tertiary amine group into the monomer molecule is responsible for the formation of cationic polyelectrolyte, e.g., poly((2-dimethylamino) ethyl methacrylate) PDMAEMA [33]. The pHresponsive polymers have been widely used in many applications, essentially in bioseparation and drug delivery [34, 35]. Both thermo-responsive and pHresponsive monomers have been copolymerized to prepare dual-responsive thermo-pH responsive polymeric materials [36, 37]. In special interests, several scientific kinds of research have been studying the copolymerization of NIPAAm with cationic or anionic monomer to optimize the general characterization of polymeric material with advantage to the lower critical solution temperature of polymer solutions $[1,2,19,20]$. Several research articles recently prepared vanillin-based monomers and its derivative due to their natural resource and nontoxic properties [38-43]. $N, N$-dimethylacrylamide (DMAA) is a hydrophilic monomer that has been copolymerized with $\mathrm{N}$-isoprpylacrlamide to enhance the hydrophilic efficiency of copolymer that reflected on the change of LCST to a higher value [9, 44-46]. The Hofmeister series, also known as the lyotropic series, was unveiled by Franz Hofmeister [47]. They have discussed the influence of the anions and cations of salts on the solubility or coagulation of proteins [48]. Anions are the most familiar used than cations; they have two major types according to their arrangement in the Hofmeister series. Chaotropes anions are singly charged and have low charge density, e.g., $\mathrm{Cl}^{-}, \mathrm{NO}_{3}{ }^{-}, \mathrm{SCN}^{-}$; they weakly interact with water molecules and order-making exhibiting the formation of hydrogen bonds and the ability of solubility. On the other hand, kosmotropes anions are small with highly charged density, e.g., $\mathrm{CO}_{3}{ }^{2-}, \mathrm{SO}_{4}{ }^{2-}, \mathrm{S}_{2} \mathrm{O}_{3}{ }^{2-}$; they strongly interact with water molecules than the self-interaction of water, forming breaking in the hydrogen bonds order-breaking [49-51]. Recently, several studies focused on Hofmeister salts' effect on the LCST and the cloud point of PNIPAAm solutions and its copolymers [52,53]. All studies unveiled the lower critical solution temperature lowered by the addition of kosmotropes; however, the effect has been weaker by using chaotropic $[54,55]$. In this work, we prepared a series of thermo-pH-salt responsive terpolymers by the copolymerization of NIPAAm, DMAA, and new tertiary pH monomer DTBAVA; in the next, this work will get many applications for bioseparation of biological molecules by one-pot reaction via Schiff's base post-polymerization.

\section{Experimental}

\subsection{Materials and instrumentation}

\subsubsection{Materials}

Acryloyl chloride, 2-propenoyl chloride or acrylic acid chloride (AC) (97\%, Sigma-Aldrich, (stabilized with phenothiazine) for synthesis, Germany), $N$ isopropylacrylamide (NIPAAm) (97\%, Sigma-Aldrich, Germany) was recrystallized from distilled n-hexane., 2,2'-Azobis(2-methylpropionitrile) (AIBN) (98\%, Sigma-Aldrich, Germany) was recrystallized from methanol, vanillin, 4-Hydroxy-3-methoxybenzaldehyde, vanillic aldehyde (V) (97\%, Sigma-Aldrich, Germany), N,N-Dimethylacrylamide (99\%, Sigma-Aldrich, Germany, contains 500 ppm monomethyl ether hydroquinone as inhibitor), di-tert-butylamine (97\%, SigmaAldrich, Germany), triethylamine (TEA) (99\%, Sigma-Aldrich, Germany), Sodium carbonate (Grüssing), magnesium sulfate (Merck), tetrahydrofuran (THF), sodium chloride, sodium sulfate, and sodium thiocyanate ( $\geq 99 \%$, Fluka-Fisher, Germany), chloroform trichloromethane $\left(\mathrm{CHCl}_{3}\right)$, and diethyl ether $\mathrm{Et}_{2} \mathrm{O}$ were distilled over potassium hydroxide. Other chemicals were used as purchased.

\subsubsection{Instrumentation}


Vertex 70 Fourier transform infrared instrument FT-IR. Bruker AV 500 spectrometer at $500 \mathrm{MHz}$ and $125 \mathrm{MHz}$ was used for recording ${ }^{1} \mathrm{H}$ and ${ }^{13} \mathrm{C}$ NMR, respectively, at $25{ }^{\circ} \mathrm{C}$; samples were dissolved in $\mathrm{CDCl}_{3}$ or $\mathrm{DMSO}-\mathrm{d}^{6}$. The dry sample was milled with $\mathrm{KBr}$ and then pressed into pellets for the measurement process.

Differential Scanning Calorimeter (DSC) Perkin Elmer Pyris 1; this technique is used to record the glass transition temperature ( $\left.T_{g}\right)$ solid polymers at heat and cool rate of $5{ }^{\circ} \mathrm{C} / \mathrm{min}$. It was recorded at the onset value of the thermogram.

Thermogravimetric analysis (TGA); was used to investigate the thermal stability of the polymer sample related to its chemical decomposition by heating from $25^{\circ} \mathrm{C}$ to $700{ }^{\circ} \mathrm{C}$ and heating rate of $5^{\circ} \mathrm{C} / \mathrm{min}$.

X-ray diffraction-(Bruker AXS D8 Advance); was used for recording the degree of crystallinity. The detector is Vantec-1; high precision microprocessorcontrolled, Goebel mirror; two circle goniometer with independent stepper motors and optical encoders, reproducibility $+/-0.0001^{\circ}$, smallest angular step $0.0001^{\circ}$, high-temperature MRI stage (RT-1400C), sample spinner, video camera, thin-film Reflectometry, sample plate fixed with 9-sample holders. The instrument was run as $2.2 \mathrm{~kW} \mathrm{Cu}$ and Co, Running $40 \mathrm{kV}, 40 \mathrm{~mA}$. The stability of power is better than $0.01 \%$.

Size exclusion chromatography (SEC) has been used for the determination of molecular weights $\left(M_{n}, M_{w}\right)$ and dispersity $(\nexists)$ in THF as eluent contaminated with 0.1 vol\% triethylamine and a flow rate of $0.75 \mathrm{~mL} / \mathrm{min}$ at $30{ }^{\circ} \mathrm{C}$. The sample was dissolved at $15 \mathrm{mg} / \mathrm{mL}$; an automatic injection ran it. PSS-SDV Columns were used with $5 \mu \mathrm{m}$ gel. The molecular weight $M_{w}$ of polystyrene (PS) was used as standard.

To measure the contact angle $(\Theta)$ : the sample was converted into a pellet and allowed a $4 \mu \mathrm{l}$ drop of $\mathrm{pH}$ solution over the sample surface using a micropipette. The photographs were taken for each drop using a digital camera. The contact angles were detected from the photographs by using the software ImageJ.

Measurements of the phase separation temperature or lower critical solution temperature (LCST) ( $\left.T_{c}\right)$ and cloud point for terpolymer solution

1. It was performed by UV-vis spectrometer (Perkin Elmer Lambda 45); it is known by the turbidity method. The process depends on the relation of transmittance and temperature of the polymer solution. The instrument has been built by metal covet stands with the water cycle and fixed using a thermostat and cooling system. The internal heat of the polymer solution was measured by a manual thermostat inside the solution at $2{ }^{\circ} \mathrm{C} / \mathrm{min}$ over the range from $5-80^{\circ} \mathrm{C}$. The polymer solution concentration was at $1 \mathrm{wt} \%$ in water or $\mathrm{pH}$ solution.

2. Another instrument was used for $T_{c}$ measurement of polymer solution; it is micro-DSC III from setaramto. The thermograms of the terpolymer solutions were recorded. The heating rate was at $5^{\circ} \mathrm{C} / \mathrm{min}$; the concentration was $50 \mathrm{mg} / \mathrm{ml}$ in deionized water. The transition temperature $T_{c}$ was detected at the onset value.

\subsection{Preparation of [2-((di-tert-butylamino) methyl)-4-formyl-6-methoxyphenyl acrylate] (DTBAVA).}

It has been synthesized in two steps as described in our recent publication [41].

\subsection{Fabrication of functionalized thermo-pH poly(NIPAAm-co-DMAA-co-DTBAVA) with 10 mol\% of DMAA and 5,10 and 20 mol\% of DTBAVA.}

\section{General Procedure}

The free radical polymerization was achieved by adding $10 \mathrm{~mol} \%(0.26 \mathrm{~g})$ of $\mathrm{N}, \mathrm{N}$-dimethylacrylamide DMAA, and 5, 10, and $20 \mathrm{~mol} \%(0.45 \mathrm{~g}, 0.92 \mathrm{~g}$, and 1.81 g) of TBAMVA initiated by 2, 2'-Azobis(2-methylpropionitrile) AIBN. All dissolved in absolute ethyl alcohol EtOH and $100 \mathrm{~mL}$ round flask. They were purged in nitrogen gas for $20 \mathrm{~min}$., stirred with heating at $75^{\circ} \mathrm{C}$ for $8 \mathrm{~h}$. The polymer solutions were precipitated in diethyl ether at $-25^{\circ} \mathrm{C}$. They were purified by dissolving in THF and then reprecipitated in diethyl ether. They are filtered off to collect pure polymers. The physical properties for all as solid color depending on the TBAMVA content from light yellow to deep yellow.

${ }^{1} \mathrm{H}$ NMR (500 MHz, CDCl 3 ): $\delta(\mathrm{ppm})=0.97-1.43(\mathrm{~m}, 19 \mathrm{H}, \mathrm{a}, \mathrm{j}-\mathrm{CH} 3), 1.45-1.83(\mathrm{~m}, 6 \mathrm{H}, \mathrm{o}, \mathrm{m}, \mathrm{k}-\mathrm{CH}$ repeating units), 1.92-2.43 (m, 6H, I, n, b-CH 2 repeating units), 2.63-3.27 (m, 6H, g-2 $\left.\mathrm{CH}_{3}\right), 3.46-3.48\left(\mathrm{~m}, 2 \mathrm{H}, \mathrm{b}-\mathrm{CH}_{2}\right), 3.84-4.15(\mathrm{~m}, 1 \mathrm{H}, \mathrm{i}-\mathrm{CH}), 6.13-7.1(\mathrm{br} ., 1 \mathrm{H}, 17-\mathrm{NH}), 5.83-6.82(\mathrm{br} ., \mathrm{m}, 1 \mathrm{H}, \mathrm{h}-\mathrm{NH}), 7.21-7.72(\mathrm{~m}, 2 \mathrm{H}, \mathrm{c}, \mathrm{d}-\mathrm{CH}-\mathrm{Ar}$ ), 9.89-10.01 (m, 1H, e-CHO).

IR (KBr): v (cm $\left.{ }^{-1}\right)$ : 3095-2985(s) (CH-Aliphatic), 1705(s) (C=0, carbonyl), 1670(s) (C=0, aldehyde), 1576(s) (C=0, amide), 1525 (s) (C=C, aromatic), 1116 (s) (O$\mathrm{CH} 3), 808-857$ (m) (CH-Aromatic).

\section{Results And Discussion}

\subsection{Monomer and polymer chemical evaluations}

The new monomer has been synthesized according to Scheme 1. The procedure was implemented in two steps. The cationic monomer from vanillin was first prepared via the reaction of vanillin, formaldehyde, and di-tert-butylamine producing compound II [3-((di-tert-butylamino)methyl)-4-hydroxy-5-methoxybenzaldehyde] (DTBAV). The evaluation has been done using the $1 \mathrm{H}, 13 \mathrm{C}$ NMR, and FT IR as discussed in our previously work [41]. Figures were added in supplementary part. The final product was formed by reacting compound II in an alkaline solution such as triethylamine in an inert atmosphere via purging nitrogen entailed the dropping of acid chloride (acryloyl chloride) for compound III (DTBAVA), all in equivalent molar concentrations; they have also been discussed recently [41]. Figures were added to the supplementary part. 
Eventually, the work has been accomplished by fabricating thermo-pH environmentally terpolymers via the free radical polymerization of $\mathrm{N}$ isopropylacrylamide and N, N-dimethylacrylamide, and three different molar concentrations of (DTBAVA) (5, 10, and 20 mol\%) in solution and initiated by AIBN. One notable was taken in the yield percentage of polymer; they decreased with increasing the molar concentration of DTBAVA in the polymer chain. The investigations of terpolymers have been performed via ${ }^{1} \mathrm{H}$ NMR and $\mathrm{FT}$ IR. Figure 1 illustrates the ${ }^{1} \mathrm{H}$ NMR of terpolymers in $\mathrm{CDCl}_{3}$, the essential $1 \mathrm{H}$ peaks and integrations were evaluated and used in the estimation of the actual molar concentration of each monomer in the chain of the terpolymer, as apparent in Table 1 ; they are $\delta=2.63-3.27 \mathrm{ppm}$ multiple peaks of dimethyl groups of $\mathrm{N}, \mathrm{N}$-dimethylacrylamide, at $\delta=3.84-4.15 \mathrm{ppm} 1 \mathrm{H}$ for $-\mathrm{CH}$ - isopropyl of $\mathrm{N}$ isopropylacrylamide, the last peak is related to $1 \mathrm{H}$ of the aldehyde of DTBAVA at $\delta=9.89-10.01$. The functional groups have also been tested via FT IR indicating different vibrations related to $-\mathrm{C}=\mathrm{O}$ ester at $\mathrm{v}=1705 \mathrm{~cm}-1, \mathrm{v}=1670 \mathrm{~cm}-1,-\mathrm{C}=0$, aldehyde group, $\mathrm{v}=1576 \mathrm{~cm}-1,-\mathrm{C}=\mathrm{O}$, the amide of $-\mathrm{CONH}-$ NIPAAm, as shown in Fig. 2.

Table 1

Yield \%, composition, molecular weight, dispersity, glass temperature, crystalinity, and transition temperature/cloud point of poly(NIPAAm-co- DMAA-co-

\begin{tabular}{|c|c|c|c|c|c|c|c|c|c|c|c|c|c|}
\hline \multirow[t]{3}{*}{ Polymer } & \multirow{3}{*}{$\begin{array}{l}\text { Yield } \\
\%\end{array}$} & \multicolumn{2}{|c|}{ Composition ${ }^{1} \mathrm{HNMR}$} & \multirow{3}{*}{$\begin{array}{l}M_{n}^{a} \\
(\mathrm{~g} / \mathrm{mol}) \\
10^{4}\end{array}$} & \multirow{3}{*}{$\begin{array}{l}M_{w}^{\mathrm{b}} \\
(\mathrm{g} / \mathrm{mol}) \\
10^{4}\end{array}$} & \multirow[t]{3}{*}{$\bigoplus^{c}$} & \multirow{3}{*}{$\begin{array}{l}T_{g}{ }^{\mathrm{d}}\left({ }^{\circ} \mathrm{C}\right) \\
\text { DSC }\end{array}$} & \multirow{3}{*}{$\begin{array}{l}\text { Cry. } \\
(\%) \\
\text { (XRD) }\end{array}$} & \multirow{2}{*}{\multicolumn{4}{|c|}{$\begin{array}{l}T_{c}{ }^{\mathrm{f}}\left({ }^{\circ} \mathrm{C}\right) / \mathrm{C}_{p} \mathrm{~g}\left({ }^{\circ} \mathrm{C}\right) \\
\text { UV }\end{array}$}} & \multirow{3}{*}{$\begin{array}{l}T_{c}{ }^{\mathrm{f}}\left({ }^{\circ} \mathrm{C}\right) \\
\mathrm{DSC} \\
\mathrm{pH} 7\end{array}$} \\
\hline & & & & & & & & & & & & & \\
\hline & & DMAA & DTBAVA & & & & & & pH 1.68 & $\mathrm{pH} 4$ & $\mathrm{pH} 7$ & pH 10.4 & \\
\hline Vla-05 & 86 & 9.3 & 3.8 & 1.4 & 3.3 & 2.3 & 141 & 53.4 & $40.6 / 41.3$ & $39 / 40.4$ & $36.3 / 37.5$ & $34.6 / 35.4$ & 35.5 \\
\hline VIb-10 & 83 & 9.0 & 7.6 & 1.4 & 2.9 & 2.2 & 135 & 48.3 & 43.7/44.6 & $42 / 43.7$ & $31.2 / 32$ & $29.8 / 30.9$ & 29.6 \\
\hline VIc-20 & 74 & 8.6 & 14.4 & 1.2 & 2.3 & 1.9 & 119 & 42 & $51.5 / 52.3$ & $49 / 50.4$ & $24.7 / 25.4$ & $22.3 / 23.6$ & 23.5 \\
\hline
\end{tabular}

Transition temperatures and cloud points affected by different concentrations of salt ions in deionized water.

\begin{tabular}{|c|c|c|c|c|c|c|c|c|c|c|c|c|c|}
\hline \multirow[t]{2}{*}{ polymer } & \multicolumn{5}{|c|}{$T_{c}{ }^{\mathrm{f}}\left({ }^{\circ} \mathrm{C}\right) / \mathrm{C}_{p}{ }^{\mathrm{g}}\left({ }^{\circ} \mathrm{C}\right) \mathrm{Na}_{2} \mathrm{SO}_{4}{ }^{\mathrm{i}}$} & \multicolumn{5}{|c|}{$T_{c}{ }^{\mathrm{f}}\left({ }^{\circ} \mathrm{C}\right) / \mathrm{C}_{p}{ }^{\mathrm{g}}\left({ }^{\circ} \mathrm{C}\right) \mathrm{NaCl}^{\mathrm{j}}$} & \multicolumn{3}{|c|}{$T_{c}{ }^{\mathrm{f}}\left({ }^{\circ} \mathrm{C}\right) / \mathrm{C}_{p}{ }^{\mathrm{g}}\left({ }^{\circ} \mathrm{C}\right) \mathrm{NaSCl}$} \\
\hline & $\begin{array}{l}0.1 \\
\text { wt.\% }\end{array}$ & $\begin{array}{l}0.2 \\
\text { wt.\% }\end{array}$ & 0.3 wt. $\%$ & 0.4 wt.\% & $\begin{array}{l}0.5 \\
\text { wt.\% }\end{array}$ & $\begin{array}{l}0.1 \\
\text { wt.\% }\end{array}$ & $\begin{array}{l}0.2 \\
\text { wt.\% }\end{array}$ & $\begin{array}{l}0.3 \\
\text { wt.\% }\end{array}$ & $\begin{array}{l}0.4 \\
\text { wt.\% }\end{array}$ & $\begin{array}{l}0.5 \\
\text { wt.\% }\end{array}$ & $\begin{array}{l}0.1 \\
\text { wt.\% }\end{array}$ & $\begin{array}{l}0.2 \\
\text { wt.\% }\end{array}$ & $\begin{array}{l}0.3 \\
\text { wt. }\end{array}$ \\
\hline Vla-05 & $30 / 31.3$ & $28.7 / 29$ & $26 / 26.8$ & $20 / 20.6$ & $17.4 / 18$ & $35 / 35.7$ & $34.6 / 35$ & $32 / 32.5$ & $30.3 / 31$ & $27.3 / 28$ & $37 / 37.8$ & $38.4 / 39$ & 40 \\
\hline Vlb-10 & $27.4 / 28$ & $26 / 27.5$ & $24.5 / 25.3$ & $19.7 / 20.4$ & $16.5 / 17$ & $30.4 / 31$ & $29 / 29.7$ & $28.4 / 28.8$ & $27.4 / 28$ & $24.5 / 25$ & $39.3 / 40$ & $40.4 / 41$ & 42 \\
\hline VIc-20 & $24.3 / 25$ & $22 / 23$ & $18 / 18.5$ & $16.6 / 17.3$ & $14.4 / 15$ & $23 / 23.6$ & $22.3 / 23$ & $21 / 21.8$ & $20.4 / 21$ & $17 / 17.9$ & $41.4 / 42$ & $43 / 444$ & 45 \\
\hline
\end{tabular}

a number average molecular weight;

${ }^{b}$ weight average molecular weight;

c dispersity;

d glass transition temperature;

e crystallinity percent

flower critical solution temperature;

${ }^{\text {gcloud point; }}$

${ }^{h}$ sodium chloride; ${ }^{i}$ sodium sulfate; ${ }^{j}$ sodium thiocyanate

\subsection{Physical properties of solid polymers}

Solid terpolymers of poly(NIPAAm-co-DMAA-co-DTBAVA) with various DTBAVA molar concentrations starting with 5 mol\%, 10 , and finally 20 mol\% have been investigated. These different molar concentrations have defiantly impacted their general characterizations.

\subsubsection{The glass transition temperature $T_{g}$ via differential scanning calorimetry (DSC)}

The glass transition temperature $T_{g}$ of polymer is a specific character like the figure print and has been influenced by other characterizations of the polymeric material. Differential scanning calorimetry DSC was used to record the glass temperature $T_{g}$ at a heating rate of $5{ }^{\circ} \mathrm{C} / \mathrm{min}$. All terpolymers were quenching from melting to liquid nitrogen temperature. The diffractogram was calibrated with standards; the glass temperature $T_{g}$ was measured at the inflected point. Figure 3 shows the diffractogram curves of terpolymer samples indicating the glass transition temperatures at 141,135 , and $119{ }^{\circ} \mathrm{C}$ for $\mathrm{Vla}$, VIb, and $\mathrm{VIC}$, respectively, as mentioned in Table 1 . The regular decrease of the $T_{g^{\prime} s}$ inflected the effect of the molar concentration of DTBAVA in the polymer main chain; the reason is the addition of aromatic monomer, which restricts the flexible rotation of repeating unit in polymer chain [56].

3.2.2. Thermal stability via thermogravimetric analysis TGA 
Thermogravimetric analysis has performed the thermal degradation of terpolymers at $10{ }^{\circ} \mathrm{C} / \mathrm{min}$ from $25-600{ }^{\circ} \mathrm{C}$. Figure $4 \mathrm{~A}$, B illustrates the thermal decompositions and their 1 st derivatives of synthetic terpolymers. The significant degradation of terpolymer Vla with 5 mol\% of DTBAVA has occurred in three steps the first from $200-250{ }^{\circ} \mathrm{C}$ for evaporator materials water and ammonia, the principle degradation was detected from $390-415{ }^{\circ} \mathrm{C}$, this is due to the decomposition of repeating unit in the polymer chain, eventually full decomposing from $495-550{ }^{\circ} \mathrm{C}$ for hydrocarbon. For terpolymer VIb 10 mol\% DTBAVA has also been exhibited three main degradable stages; the first has occurred from $130-170{ }^{\circ} \mathrm{C}$, the next one from $365-385{ }^{\circ} \mathrm{C}$ refereeing to the principal decomposition of the polymer chain, and finally $520-555^{\circ} \mathrm{C}$. The higher molar concentration of 20 mol\% of DTBAVA VIc demonstrated the first degradation from $135-180^{\circ} \mathrm{C}$; however, the principle degradation of polymer chains showed different feature; it exhibited two distinct degradations as shown in Fig. $8 \mathrm{~B}$, from $325-360{ }^{\circ} \mathrm{C}$, and from $365-390{ }^{\circ} \mathrm{C}$, this might be attributed to the decomposition of the polymer chain in two stages at the lowest temperature for DTBAVA repeating unit, while the highest to NPAAm and DMAA. The complete decompose has been detected from the range like lately of VIb terpolymer.

\subsubsection{Degree of crystallinity via X-ray diffraction XRD}

The crystallization process and the degree of crystallinity differentiate among the state of the material that is crystalline, semi-crystalline, or amorphous. Figure 5 illustrates the crystallographic analysis of XRD of new synthetic terpolymers Vla-c. Diffraction peaks at $2 \theta=25^{\circ}$ to $37^{\circ}$ and $38^{\circ}$ to $47^{\circ}$ are attributed to the enhancement of the crystallization. The crystallinity percent has been calculated for each terpolymer via the crystallographic by (area of crystalline peaks/area of all peaks x 100) [57]. They demonstrated crystallinity\% of 53.4, 48.3, and $42 \%$ for Vla, VIb, and VIc, respectively. The essential feature of the crystallographic is the absence of the sharpest peak indicating the semi-crystalline state. One other note is that the correlation of crystallinity on the molar concentration of DTBAVA demonstrated a reversible process, increasing steric hindrance and restricted rotation sparked by increasing DTBAVA.

\subsection{Terpolymer solution}

\subsubsection{Molecular weight/dispersity}

Gel permeation chromatography is used to measure the molecular weight (weight average molecular weight $M_{w}$ and number average molecular weight $M_{n}$ ) and dispersity $M_{w} / M_{n}, \oplus$ for all polymeric samples dissolving in THF and using PS as standard. The chromatogram analysis has shown a good responsibility of the detector with the retention time. Figure 6 illustrated log $[M]$ distributions against $M n, M w$. It has also demonstrated an essential feature as the formation of one peak for each sample, indicating monomers' disappearance [1, 2]. From data summarized in Table 1, the number average molecular weight $M_{n}$ and dispersity $\oslash$ for all terpolymers; it was observed an opposite relationship of $M_{n}$ and dispersity $\Theta$ with a polymer content of DTBAVA monomer in the chain that attributed to the aromaticity steric hindrances caused a reduction in the flexibility of polymer solution [5].

\subsubsection{Terpolymers contact angles}

The effect of incorporating hydrophilic and hydrophobic groups in the terpolymers has been studied by measuring the contact angles, which is the key to recognizing the tendency of polymeric material to hydrophilicity or hydrophobicity [58]. A recent study has been interpreted the difference among hydrophilic, hydrophobic, and superhydrophobic polymeric material via the determination of their contact angles; it has shown the hydrophilic polymers should be at $\Theta<$ $90^{\circ}$, and hydrophobic at $\Theta \otimes 90^{\circ}$; however, superhydrophobic always measured at $\Theta \geq 145^{\circ}$ [58]. The measurements of the contact angles of terpolymers Vla, $\mathrm{VIb}$, and Vlc with 5,10 , and 20 mol\% of DTBAVA showed the influence of terpolymer on the DTBAVA content in the terpolymer chain in various pH solutions. Table 3 cleared all data of contact angles. For terpolymer Vla exhibited $83.5^{\circ}, 86.5^{\circ}, 84.6^{\circ}$, and $96.4^{\circ}$ in $\mathrm{pH} 1.68, \mathrm{pH} 4$, $\mathrm{pH} 7$, and pH 10.4 , respectively; the hydrophilicity decreased by increasing the $\mathrm{pH}$ from strong acidic solution to strong alkaline solution. Increasing the molar concentration of DTBAVA in the polymer chain; showed the hydrophilic property in strong acid at pH 1.68 and lower contact angle $\Theta \sim 82^{\circ}$ than Vla attributed to the effect of ionization of tertiary amine group in acidic solution. It is increased regularly in higher pH solutions. The highest hydrophilicity was detected for terpolymer Vlc at the strongest acidic solution $\mathrm{pH} 1.68$ and the lowest contact angle at $\Theta \sim 80.8^{\circ}$; the reason has been interpreted as previously discussed. Figures 7 and 8 describe the relationship between the contact angles of all terpolymers with the $\mathrm{pH}$ change.

Table 3

Contact angle and wettability of polymers in different

$\mathrm{pH}$

\begin{tabular}{|lllll|}
\hline \multicolumn{3}{|l|}{$(\Theta)^{\mathrm{a}} \sim \mathbf{0 . 2}^{\circ}$} \\
\hline Polymer & $\mathrm{pH} 1.68$ & $\mathrm{pH} 4$ & $\mathrm{pH} 7$ & $\mathrm{pH} 10.4$ \\
\hline Vla-05 & $83.5^{\circ}$ & $86.5^{\circ}$ & $84.6^{\circ}$ & $96.4^{\circ}$ \\
\hline Vlb-10 & $82^{\circ}$ & $88^{\circ}$ & $94.4^{\circ}$ & $107.6^{\circ}$ \\
\hline Vlc-20 & $80.8^{\circ}$ & $81.7^{\circ}$ & $120.8^{\circ}$ & $122.5^{\circ}$ \\
\hline a Contact angle & & & \\
\hline
\end{tabular}

\subsubsection{The impact of $\mathrm{pH}$ solutions on the phase separation temperature and the cloud points}

Two methods were used to identify and measure the lower critical solution temperature and the cloud point. The first method via turbidity test was UV/vis spectroscopy; the relation between transmittance percent to temperature, as shown in Fig. 9A-D, represents the transition temperature $T_{C}$ at the inflected point and the cloud point $C_{p}$ at the mid transmittance to temperature (50\%). The hydrophilic/hydrophobic balance in the terpolymers inflected the presence of hydrophilic groups besides the hydrophobic in NIPAAm, DMAA, and DTBAVA monomers; moreover, the sensitivity of these terpolymers towards the pH solution. All have been affected by the fluctuations of both the transition temperatures and the cloud point of the terpolymer solution. The terpolymers 
solution in $\mathrm{pH} 1.68$ were demonstrated the highest $T_{c^{\prime} s}$ and $C_{p^{\prime} s}$ for terpolymers under investigation. They exhibited $40.5,43.7$, and $51.5^{\circ} \mathrm{C}$ for $T_{c^{\prime} s}$ corresponding to $C_{p^{\prime} s}$ at $41.3,44.6$, and $52.3^{\circ} \mathrm{C}$ for $\mathrm{Vla}$, VIb, and $\mathrm{Vlc}$, as shown in Fig. 9A. The regular raising in both $T_{c^{\prime} s_{\text {, }}}$ and $C_{p^{\prime} s}$ was detected by increasing the molar concentrations of DTBAVA due to the domination of the hydrophilic chains acting in the cationic tertiary amine that increase the hydrogen bonding in the terpolymer solutions. Figure $13 \mathrm{~B}$ has recorded the $T_{c^{\prime} s_{1}}$ and $C_{p^{\prime} s}$ in the $\mathrm{pH} 4$ for all terpolymers. By going from the strongest acidic solution to the weaker one; the obtained $T_{c^{\prime} s}$ and $C_{p^{\prime} s}$ have demonstrated lower values, $39,42,49{ }^{\circ} \mathrm{C}$, and $40.4,43.7,50.4{ }^{\circ} \mathrm{C}$ for each of $T_{c^{\prime} s}$, and $C_{p^{\prime} s^{\prime}}$ respectively, as illustrated in Fig. 9B. These results reflected the same reasons discussed later. In the neutral solution via pH 7 solution, the $T_{c^{\prime} s^{\prime}}$ and $C_{p^{\prime} s}$ were tested. The general feature was observed in the disappearance of the cationic tertiary amine in the terpolymer solution affected by slow down $T_{c^{\prime} s}$, and $C_{p^{\prime} s}$ reached to the lowest temperature with VIc, 20 mol\% of DTBAVA. The recorded data were $36.3,31.3$, and $24.7{ }^{\circ} \mathrm{C} T_{c^{\prime} s}$ to $37.5,32$, and $25.4{ }^{\circ} \mathrm{C} C_{p}{ }^{\prime}$, Fig. $9 \mathrm{C}$. The last test was achieved in a strong alkaline $\mathrm{pH} 10.4$ solution. The resulted $T_{c^{\prime} s}$ and $C_{p^{\prime} s}$ are $34.6,29.8,22.3$, and $34.4,30.9,23.5^{\circ} \mathrm{C}$, respectively. They exhibited the same behavior as in the previous test. Both cases showed the domination of the hydrophobic groups and the weakness of hydrogen bonding [13, 15]. The Confirmation of the last tests, a micro-DSC for terpolymers in $\mathrm{pH} 7$ has been performed. They exhibited the $T_{c^{\prime} \text { s }}$ as the onset point of the diffractogram at $35.5,29.6$, and $23.5^{\circ} \mathrm{C}$ for $\mathrm{Vla}, \mathrm{VIb}$, and VIc, respectively. A slight difference in the $T_{c}^{\prime}$ s values recorded by micro-DSC to values obtained by the turbidity test interpreted to the different methods used to determine $T_{c^{\prime} s}$ such as inflected point or onset point, as shown in Fig. $10[5,13]$.

\subsubsection{The impact of salt concentrations of Hofmeister anions on the LCST/C $p$.}

The effects of Hofmeister anions and salt concentrations on the lower critical solution temperature and the cloud point have been urged in this study. The turbidity test was used to measure both of $T_{c^{\prime} s}$ and $C_{p^{\prime} s}$ by the UV-vis spectrophotometer at $500 \mathrm{~nm}$ wavelength. Different weight percent concentrations ( $0.1-$ 0.5 wt.\%) sodium sulfate $\left(\mathrm{Na}_{2} \mathrm{SO}_{4}\right)$ acting kosmotropes anion, sodium chloride $(\mathrm{NaCl})$, and sodium thiocyanate ( $\left.\mathrm{NaSCN}\right)$ as chaotropic anions; they were dissolved in aqueous solutions. The transmittances versus the temperatures were used to detect the $T_{c^{\prime} s}$, and $C_{p^{\prime} s^{\prime}}$ as shown in Fig. 11 . The transmittance vs. temperatures of terpolymers Vla-05, Vla-10, Vla-20 dissolved in aqueous solutions $0.1-0.5 \mathrm{wt} . \% \mathrm{Na}_{2} \mathrm{SO}_{4}$ were measured as illustrated in Fig. $11 \mathrm{~A}$; the transition temperatures $T_{c^{\prime} S^{\prime}}$ and the cloud points $C_{p^{\prime} s}$ exhibited the highest value for $0.1 \mathrm{wt} \% \mathrm{Na}_{2} \mathrm{SO}_{4}(\mathrm{Vla}-05)$ at $30 / 31.3{ }^{\circ} \mathrm{C} T_{d} C_{p}$, the lowest value was recorded for $0.5 \mathrm{wt} . \% \mathrm{Na}_{2} \mathrm{SO}_{4}(\mathrm{VIc}-20)$ at $14.4 / 15^{\circ} \mathrm{C} T_{d} C_{p}$. These measurements proved the effect of kosmotropes anion on the breaking of hydrogen bonding of the amide group in PNIPAAm and blocking the interaction of the tertiary amine group of DTBAVA. Overall has made the domination of the hydrophobic groups faster the turbidity and the phase separation of polymer molecules from solution [50-53]. The change of polymer solution from kosmotropes to chaotropic has influenced the transition temperature and the cloud points of terpolymers. The solubility of terpolymers in NaCl with different weight percent $0.1-0.5 \mathrm{wt}$ \% was implemented, and the transmittances vs. temperatures were recorded. In this state, lower spiky was observed in the transition temperature and the cloud points than observed with Na2SO4 solutions, as shown in Fig. 11B; the $T_{c} / C_{p}$ has fluctuated to record the highest value for $0.1 \mathrm{wt}$.\% $\mathrm{NaCl}(\mathrm{Vla}-05)$ at $35 / 35.7^{\circ} \mathrm{C}$, and the lowest at $17 / 17.9^{\circ} \mathrm{C}$ for $0.5 \mathrm{wt} . \% \mathrm{NaCl}$ (VIc-20); the interpretation of results has been discussed lately. Conversely, the solubility of terpolymers in sodium thiocyanate solutions has been seen in Fig. $11 \mathrm{C}$. The strongest spiky for the $T_{c^{\prime} s} / C_{p^{\prime} s}$ was detected at $52 / 53{ }^{\circ} \mathrm{C}$ for 0.5 wt.\% NaSCN (VIc-20). The much higher hydrophilic groups based on the interaction of the thiocyanates anions with amide group (NIPAAm) as well as the aldehyde group (DTBAVA) producing structure-making and increased the solubility of terpolymers, and therefore slowed the phase separation process to higher temperature [56, 58]. All data has been summarized in Table 2. Figure 11D illustrated the relationship between the LCST ( $\left.T_{c^{\prime} s}\right)$ and weight percent concentrations of terpolymer solutions with $\mathrm{Na}_{2} \mathrm{SO}_{4}, \mathrm{NaCl}$, and $\mathrm{NaSCN}$ showing the highest $T_{c}{ }^{\prime} / C_{p}{ }^{\prime} s$ terpolymer VIc-20 dissolved in 0.5 wt.\% NaSCN, while the lowest one for terpolymer Vlc-20 dissolved in $0.5 \mathrm{wt} . \% \mathrm{Na}_{2} \mathrm{SO}_{4}$.

\section{Conclusion}

First, the new monomer DTBAVA was prepared from vanillin in two facile methods; the chemical structure was confirmed by suitable instruments that achieved good results. Three thermo-pH responsive terpolymers were designed from NIPAAm, DMAAm, and DTBAVA. The terpolymerization process was made by free radical polymerization using different molar concentrations of DTBAVA 5, 10, and $20 \mathrm{~mol} \%$, Vla, VIb, and VIc, respectively. The general physical characterizations were performed; the glass transition temperature $T_{g}$, molecular weight, and dispersity demonstrated their reversible relation with the content of DTBAVA in the polymer chain. Furthermore, the crystallinity by XRD has also been represented a lower crystallinity percent with increasing DTBAVA. The degradation steps have illustrated two steps with Vla, Vlb, and three steps with Vlc. The contact angle was determined in different $\mathrm{pH}$ solutions that exhibited the highest and lowest hydrophilic values for VIc in pH 10.4. The lowest contact angle and the highest hydrophilic were also seen for VIc at pH 1.68. The phase separation temperature of terpolymers was tested in various $\mathrm{pH}$ solutions and different Hofmeister salt via UV/vis spectroscopy. They have been demonstrated the highest $T_{c}$ in $\mathrm{pH} 1.68$ for VIc, 20 mol\% DTBAVA, depending on the ionization of tertiary amine group; however, the lowest value has also seen at $\mathrm{pH} 10.4$ for the same terpolymer. Micro-DSC of polymer solution in $\mathrm{pH} 7$ was used to assure the $T_{c}$ results based on UV/vis spectroscopy. The salt effect was tested using three solutions of salts from kosmotropic as $\mathrm{Na}_{2} \mathrm{SO}_{4}$, chaotropic $\mathrm{NaCl}$, and $\mathrm{NaSCN}$. The study illustrated the structure-breaking of $\mathrm{Na}_{2} \mathrm{SO}_{4}$ terpolymer solution by recording the lowest transition temperature with the highest concentration of salt. Otherwise, the lowest $T_{C}$ value has been detected for terpolymer in chaotropic NaSCN solution with the highest salt concentration and the highest DTBAVA molar concentration. Future research will be interested in applying these terpolymers in the separation process of biological molecules.

\section{Declarations}

\section{Acknowledgments}

I want to thank the University of Paderborn. 


\section{Conflicts of Interest}

The authors declare that there are no conflicts of interest regarding the publication of this paper.

\section{References}

1. Abdelaty MSA (2020) Influence of vanillin acrylate and 4-acetylphenyl acrylate hydrophobic functional monomers on phase separation of Nisopropylacrylamide environmental terpolymer: fabrication and characterization. Polym Bull 77:2905-2922. https://doi.org/10.1007/s00289-019-02890-0

2. Abdelaty MSA (2021) Trends in the Phase Separation Temperature Optimization of a Functional and Thermo-pH Responsive Terpolymer of Poly (Nisopropylacrylamide-co-N-(2-(dimethylamino)ethyl) Acrylamide-co-vanillin Acrylate). J Polym Environ. https://doi.org/10.1007/s10924-021-02096-4

3. Gao Y, Wei M, Li X et al (2017) Stimuli-responsive polymers: Fundamental considerations and applications. Macromol Res 25:513-527. https://doi.org/10.1007/s13233-017-5088-7

4. Fang FF, Lee BM, Choi HJ (2010) Electrorheologically intelligent polyaniline and its composites. Macromol Res 18:99-112. https://doi.org/10.1007/s13233-009-0198-5

5. Abdelaty MSA, Kuckling D (2016) Synthesis and Characterization of New Functional Photo Cross-Linkable Smart Polymers Containing Vanillin Derivatives. Gels 2:1-13. DOI:10.3390/gels2010003

6. Zhang C-L, Cao F-H, Wang J-L, Yu Z-L, Ge J, Lu Y, Wang Z-H, and Shu-Hong Yu (2017). Highly Stimuli-Responsive Au Nanorods/Poly(Nisopropylacrylamide) (PNIPAM) Composite Hydrogel for Smart Switch. ACS Applied Materials \& Interfaces. 9 (29), 24857-24863. DOI: 10.1021/acsami.7b05223

7. Fabrice O, Mohamad T, Noureddine L, Émilie G, Denis M, Abdelhamid E (2021) pH-sensitive polymers: Classification and some fine potential applications. Polym Adv Technol 32:4, 1455-1484. https://doi.org/10.1002/pat.5230

8. Ilgin P, Ozay H, Ozay O (2020) Synthesis and characterization of pH responsive alginate based-hydrogels as oral drug delivery carrier. $\mathrm{J}$ Polym Res $27: 251$. https://doi.org/10.1007/s10965-020-02231-0

9. Abdelaty MSA (2021) A Facile Method for the Preparation of Hydrophilic-Hydrophobic Functional Thermo-pH Responsive Terpolymers Based on Poly (NIPAAm-co-DMAA-co-DMAMVA) and Post-polymerization. J Polym Environ 29:3227-3241. https://doi.org/10.1007/s10924-021-02117-2

10. Ghilan A, Chiriac AP, Nita LE et al (2020) Trends in 3D Printing Processes for Biomedical Field: Opportunities and Challenges. J Polym Environ 28:13451367. https://doi.org/10.1007/s10924-020-01722-x

11. Low SC, Ng QH, Tan LS (2019) Study of magnetic-responsive nanoparticle on the membrane surface as a membrane antifouling surface coating. J Polym Res 26:70. https://doi.org/10.1007/s10965-019-1734-4

12. Karimi M, Zangabad S, Ghasemi P, Amiri A, Bahrami M, Malekzad M, Asl HGhahramanzadeh, Mahdieh H, Bozorgomid Z, Ghasemi M, Rahmani Taji Boyuk A, Hamblin MR, M. R (2016) Temperature-Responsive Smart Nanocarriers for Delivery Of Therapeutic Agents: Applications and Recent Advances. ACS Appl Mater Interfaces 8(33):21107-21133. https://doi.org/10.1021/acsami.6b00371

13. Schild HG (1992) "Poly(N-isopropylacrylamide): Experiment, theory and application". Prog Polym Sci 17(2):163-249. doi:10.1016/0079-6700(92)90023-R

14. Halperin A, Kröger M, Winnik FM (2015) "Poly(N-isopropylacrylamide) Phase Diagrams: Fifty Years of Research". Angew Chem Int Ed Engl 54(51):1534215367. doi:10.1002/anie.201506663

15. Heskins M, Guillet JE (1968) Solution Properties of Poly(N-isopropylacrylamide). J Macromolecular Sci Part A 2(8):1441-1455. doi:10.1080/10601326808051910

16. Minwoo N, Sunah K, Yeongbong M, So Jung C, Jeongseon P, Jannick K, Ji-Hun S, Yan L (2016) Upper critical solution temperature (UCST) phase transition of halide salts of branched polyethylenimine and methylated branched polyethylenimine in aqueous solutions. Chem Commun 52:509-512. https://doi.org/10.1039/C5CC08005C

17. Jukka N, Heikki T (2017) How to manipulate the upper critical solution temperature (UCST)? Polym Chem 8:220-232. https://doi.org/10.1039/C6PY01612J

18. Lanzalaco S, Armelin E (2017) Poly(N-isopropylacrylamide) and Copolymers: A Review on Recent Progresses in Biomedical Applications. Gels. ;3(4):36. Published 2017 Oct 4. doi:10.3390/gels3040036

19. Abdelaty MSA (2021) Poly(N-isopropylacrylamide-co-2-((diethylamino)methyl)-4-methylphenyl acrylate) thermo-ph responsive copolymer: trend in the lower critical solution temperature optimization of Poly (N-isopropyylacrylamide). J Polym Res 28:213. https://doi.org/10.1007/s10965-021-02574-2

20. Abdelaty MSA (2020) The Effect Hydrophilic/Hydrophobic Interaction of 2((Dimethylamino)methyl)4formyl6 methoxyphenyl Acrylate and 4Acetylphenyl Acrylate Monomers on the Phase Transition Temperature of Nisopropylacrylamide Terpolymers.J Polym Environ28:25842598https://doi.org/10.1007/s10924-020-01790-z

21. Abd El-Mohdy HL (2013) Thermo-responsive behavior of radiation-induced poly(N-isopropylacrylamide)/polyethylene oxide nanocomposite. J Polym Res 20:206. https://doi.org/10.1007/s10965-013-0206-5

22. Abdelaty MSA (2018) Preparation and Characterization of New Environmental Functional Polymers Based on Vanillin and N-isopropylacrylamide for Post Polymerization. J Polym Environ 26:636-646. DOI.org/10.1007/s10924-017-0960-2

23. Avraham H, Martin K, and FranÅoise M. W (2015) Poly(N-isopropylacrylamide) Phase Diagrams: Fifty Years of Research. Angew Chem Int Ed 54:1534215367. https://doi.org/10.1002/anie.201506663

24. Abdelaty MSA (2018) Environmental Functional Photo-cross-linked Hydrogel Bilayer Thin films From Vanillin (Part 2): Temperature responsive layer A, Functional, Temperature and pH layer B. Polym Bull 11:4837-4858. DOI: 10.1007/s00289-018-2297-y

Page $7 / 12$ 
25. Abdelaty MSA (2020) The Influence of Vanillin Acrylate Derivative on the Phase Separation Temperature of Environmental Photo-Cross-Linked Nisopropylacrylamide Copolymer and Hydrogel Thin Films.J Polym Environ. 28,2599-2615. https://doi.org/10.1007/s10924-020-01793-w

26. Choi C, Jang MK, Nah JW (2007) Preparation and characterization of nanoparticles using poly(N-isopropylacrylamide)-poly( $\varepsilon$-caprolactone) and poly(ethylene glycol)-poly( $\varepsilon$-caprolactone) block copolymers with thermosensitive function. Macromol Res 15:623-632.

https://doi.org/10.1007/BF03218942

27. Xu F, Yan TT, Luo YL (2011) Synthesis and micellization of thermosensitive PNIPAAm-b-PLA amphiphilic block copolymers based on a bifunctional initiator. Macromol Res 19:1287-1295. https://doi.org/10.1007/s13233-011-1209-X

28. Xiaowei W, Yaxuan G, Qi L, Yapeng X, Yifan S, Zheran W, Mingyu X, Ji L, Dongkai W (2022) Synergistic chemo-photothermal cancer therapy of pHresponsive polymeric nanoparticles loaded IR825 and DTX with charge-reversal property. Colloids Surf B 209(2):112164. https://doi.org/10.1016/j.colsurfb.2021.112164

29. Orakdogen N, Celik T (2016) lon-stimuli responsive dimethylaminoethyl methacrylate/hydroxyethyl methacrylate copolymeric hydrogels: mutual influence of reaction parameters on the swelling and mechanical strength. J Polym Res 23:57, 1-17. https://doi.org/10.1007/s10965-016-0946-0

30. Kyobum K, William CWC, Yunhoe H, Yadong W (2016) Polycations and their biomedical applications. Prog Polym Sci 60:18-50. https://doi.org/10.1016/j.progpolymsci.2016.05.004

31. Reyes-Ortega F (2014) pH-responsive polymers: properties, synthesis and applications, Editor(s): María Rosa Aguilar, Julio San Román, Smart Polymers and their Applications. Woodhead Publishing 45-92. https://doi.org/10.1533/9780857097026.1.45

32. Gupta P, Purwar R (2020) Electrospun pH responsive poly (acrylic acid-co- acrylamide) hydrogel nanofibrous mats for drug delivery. J Polym Res 27:296. https://doi.org/10.1007/s10965-020-02236-9

33. Yoshida E (2018) Preparation of giant vesicles containing quaternary ammonium salt of 2-(dimethylamino)ethyl methacrylate through photo nitroxidemediated controlled/living radical polymerization-induced self-assembly. J Polym Res 25, 109. https://doi.org/10.1007/s10965-018-1509-3

34. Annika H, Juan MG, Gabriel SL (2018) Use of pH Gradients in Responsive Polymer Hydrogels for the Separation and Localization of Proteins from Binary Mixtures. Macromolecules 51(20):8205-8216. DOI: 10.1021/acs.macromol.8b01876

35. Najafipour A, Mahdavian AR, Aliabadi HS et al (2020) Dual thermo- and pH-responsive poly(N-isopropylacrylamide-co-(2-dimethylamino) ethyl methacrylate)-g-PEG nanoparticle system and its potential in controlled drug release. Polym Bull 77:3129-3142. https://doi.org/10.1007/s00289-01902895-9

36. Siddique AB, An JW, Kim HJ et al (2017) Synthesis of dual stimuli-responsive polymers through atom transfer radical mechanism in aqueous media. Macromol Res 25:70-78. https://doi.org/10.1007/s13233-017-5004-1

37. He Z, Dahui S, Yajun T, Jihang Y, Xiaowei Y, Mei Z (2018) Thermo/pH dual-responsive core-shell particles for apatinib/doxorubicin controlled release: preparation, characterization and biodistribution. J Mater Chem B 6:7621-7633. DOI https://doi.org/10.1039/C8TB02334D

38. Abdelaty MSA (2018) Environmental Functional Photo-Cross-Linked Hydrogel Bilayer Thin Films from Vanillin. J Polym Environ 26:2243-2256. DOI: 10.1007/s10924-017-1126-y

39. Abdelaty MSA (2018) Poly(N-isopropylacrylamide-co-2-((diethylamino)methyl)-4 formyl-6-methoxyphenylacrylate) Environmental Functional Copolymers: Synthesis, Characterizations, and Grafting with Amino Acids. Biomolecules 8:138. doi:10.3390/biom8040138

40. Abdelaty MSA (2018) Environmental Functional Photo-Cross-Linked Hydrogel Bilayer Thin Films from Vanillin. J Polym Environ 26:2243-2256. https://doi.org/10.1007/s10924-017-1126-y

41. Abdelaty MSA (2019) Layer by Layer Photo-Cross-Linked Environmental Functional hydrogel Thin Films Based on Vanillin: Part 3. J Polym Environ 27:1212-1225. https://doi.org/10.1007/s10924-019-01421-2

42. Maxence F, Emilie D, Vincent B, Rémi A, Sylvain C, Bernard B (2014) Vanillin, a promising biobased building-block for monomer synthesis. Green Chem 2014:16, 1987-1998. https://doi.org/10.1039/C3GC42613K

43. Robin K, Volkmar MS, Carsten C, Dominik M, Detlef S, Jens T (2021) Electrochemical synthesis of biobased polymers and polymer building blocks from vanillin. RSC Adv 11:8970-8985. https://doi.org/10.1039/D1RA00649E

44. Shen Z, Terao K, Maki Y, Dobashi T, Ma G, Yamamoto T (2006) Synthesis and phase behavior of aqueous poly(N-isopropylacrylamide-co-acrylamide), poly(N-isopropylacrylamide-co-N, N-dimethylacrylamide) and poly(N-isopropylacrylamide-co-2-hydroxyethyl methacrylate). Colloid Polym Sci 284(9):1001-1007. https://doi.org/10.1007/s00396-005-1442-y

45. Akhmetzhan A, Myrzakhmetova N, Amangeldi N, Kuanyshova Z, Akimbayeva N, Dosmaganbetova S, Toktarbay Z, Longinos SN (2021) A Short Review on the N,N-Dimethylacrylamide-Based Hydrogels. Gels 7(4):234. https://doi.org/10.3390/gels7040234

46. Yinlei L, Shuoqi W, Sheng S, Yaoheng L, Yisheng X, Huawen H, Jie L, Haichen Z, Guangji L (2021) Highly tough and rapid self-healing dual-physical crosslinking poly(DMAA-co-AM) hydrogel. RSC Adv 11:32988-32995. https://doi.org/10.1039/D1RA05896G

47. Hofmeister F (1888) Hofmeister, F. Zur Lehre von der Wirkung der Salze. Arch. Exp

48. Von Hippel PH, Schleich T (1969) lon effects on the solution structure of biological macromolecules. Acc Chem Res 2:257. https://doi.org/10.1021/ar50021a001

49. Zhang Y, Cremer PS (2006) Interactions between macromolecules and ions: The Hofmeister series. Curr Opin Chem Biology 10:658. DOI: 10.1016/j.cbpa.2006.09.020

50. Kunz W, Lo Nostro P, Ninham BW (2004) The present state of affairs with Hofmeister effects. Curr Opin Colloid Interface Sci 9:1-18. doi:10.1016/j.cocis.2004.05.004

Page $8 / 12$ 
51. Zhang Y, Furyk S, Sagle LB, Cho Y, Bergbreiter DE, Cremer PS (2007) Effects of Hofmeister Anions on the LCST of PNIPAM as a Function of Molecular Weight. J Phys Chem C 111:8916. DOI: 10.1021/jp0690603

52. Shirin F, Nodar A-M, Kaizheng Z, Anna-Lena K, Bo N (2012) Effects of Hofmeister anions on the flocculation behavior of temperature-responsive poly(Nisopropylacrylamide) microgels. Colloid Polym Sci 290:1609-1616. DOI 10.1007/s00396-012-2689-8

53. Maria CMC, Sérgio MCS, Filipe EA (2015) Adjusting the low critical solution temperature of poly(N-isopropyl acrylamide) solutions by salts, ionic surfactants and solvents:A rheological study.Journal of Molecular Liquids210:113-118. http://dx.doi.org/10.1016/j.molliq.2015.02.008

54. Liusheng Z, Jianhua H, Changchun W, Shoukuan F, Meifang L (2002) The effect of electrolyte on the colloidal properties of poly(N-isopropylacrylamidecodimethylaminoethylmethacrylate) microgel latexes. Colloid Polym Sci 280:1116-1121. DOI 10.1007/s00396-002-0734-8

55. Younhee C, Yanjie Z, Trine C, Laura BS, Ashutosh C, Paul S, Cremer (2008) Effects of Hofmeister Anions on the Phase Transition Temperature of Elastinlike PolypeptidesJ. Phys. Chem. B, 112,13765-13771

56. Pérez E, Bello A, Pereña JM (1988) Substituent effect on the glass transition temperature of polyoxetanes. Polym Bull 20:291-296.

https://doi.org/10.1007/BF00261983

57. Doumeng M, Makhlouf L, Berthet F, Marsan O, Delbé K, Denape J, Chabert F (2021) A comparative study of the crystallinity of polyetheretherketone by using density, DSC, XRD, and Raman spectroscopy techniques. Polym Test 93106878. https://doi.org/10.1016/j.polymertesting.2020.106878

58. Law KY Definitions for Hydrophilicity, Hydrophobicity, and Superhydrophobicity: Getting the Basics Right. J Phys Chem Lett. 2014 Feb 20, 686-8. doi: 10.1021/jz402762h. PMID: 26270837

\section{Scheme}

Scheme 1 is available in the Supplementary Files section.

\section{Figures}

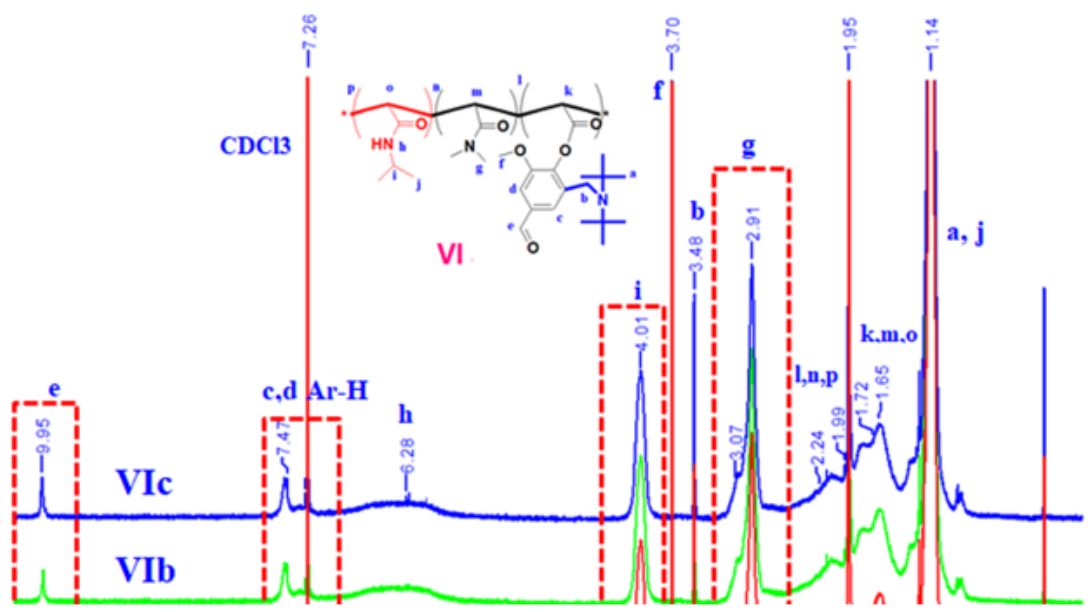

Figure 1

${ }^{1} \mathrm{H}$ NMR $\left(\mathrm{CDCl}_{3}\right)$ of terpolymers poly(NIPAAm-co-DMAA-co-DTBAVA) with $10 \mathrm{~mol} \%$ of DMAA and 5,10 and 20 mol\% of DTBAVA. 


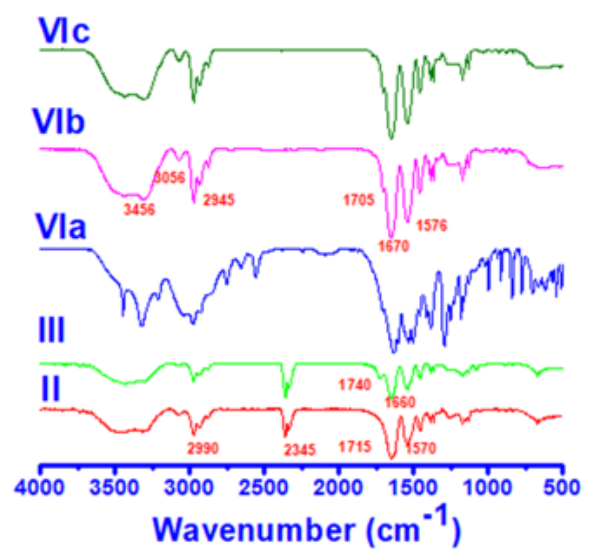

Figure 2

FT IR spectra of monomer II, III and terpolymers Vla, VIb, and VIc.

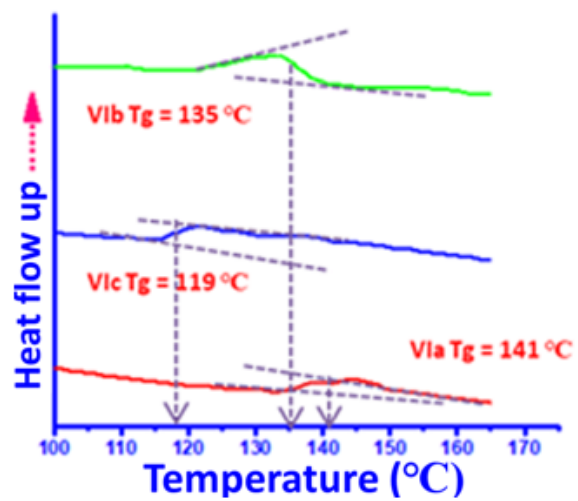

Figure 3

$T_{g}$ measurements from DSC diffractogram for terpolymers Vla, Vlb, and VIc.
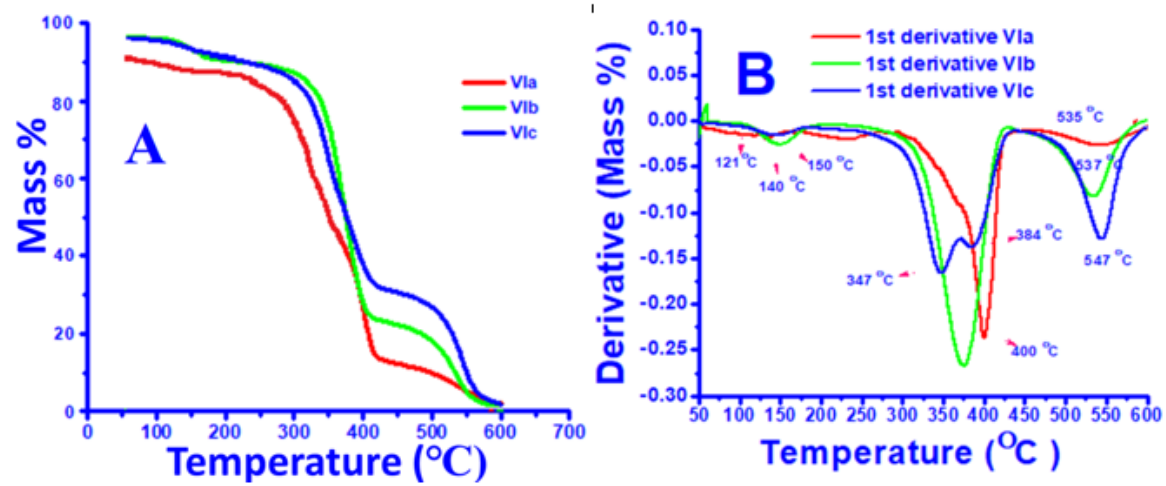

Figure 4

A, B: TGA degradation steps of terpolymers and their $1^{\text {st }}$ derivatives. 


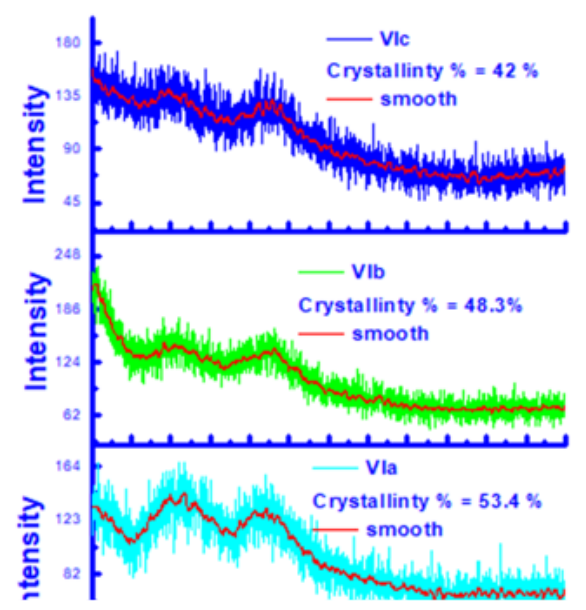

Figure 5

XRD of terpolymers Vla, Vlb, and VIc and their crystallinity percent.

Figure 6

The molecular weights of terpolymer via GPC.

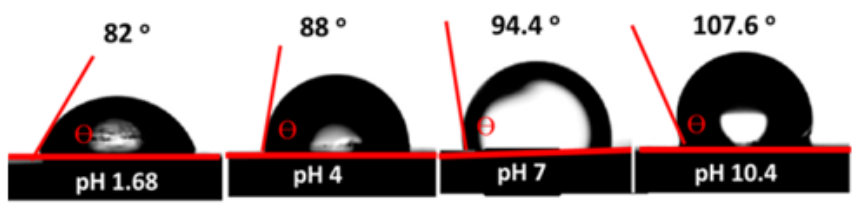

Figure 7

The contact angle photographs of polymer Vla-10 at different $\mathrm{pH}$ solutions.

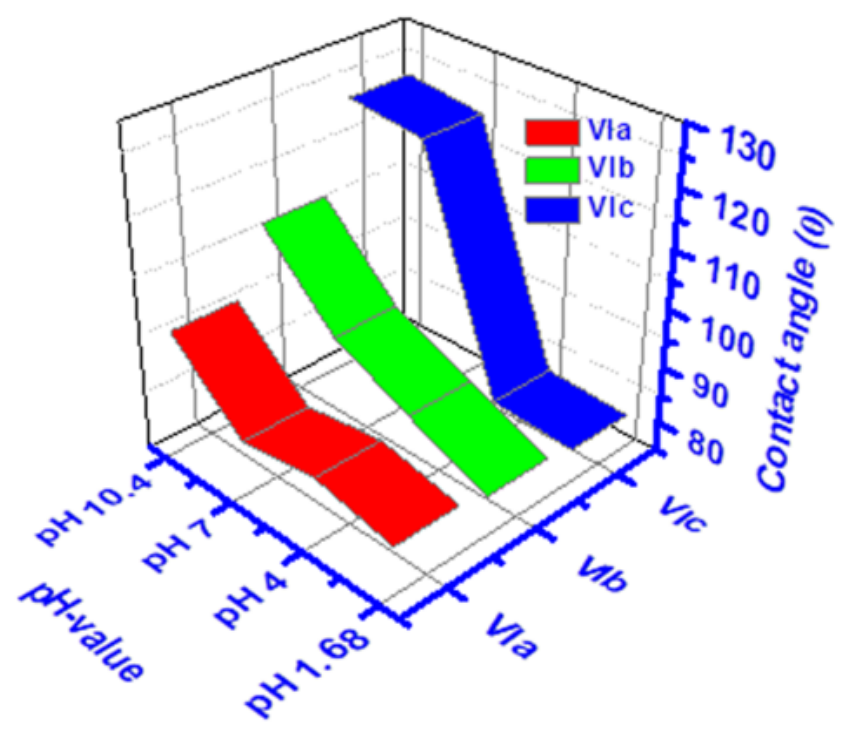


Figure 8

The relationship of contact angles $\left(\Theta^{\circ}\right)$ with $\mathrm{pH}$ value for terpolymer $\mathrm{Vla}$, VIb, and Vlc.

Figure 9

A-D: the turbidity tests of terpolymer $\mathrm{Vla}, \mathrm{Vlb}$, and $\mathrm{Vlc}$ in various $\mathrm{pH}$ solutions via the relationship of transmittance with the temperature change; $\mathbf{A}$ in $\mathrm{pH} 1.68$, $\mathbf{B}$ in $\mathrm{pH} 4, \mathbf{C}$ in $\mathrm{pH} 7$, and $\mathbf{D}$ in $\mathrm{pH} 10.4$.

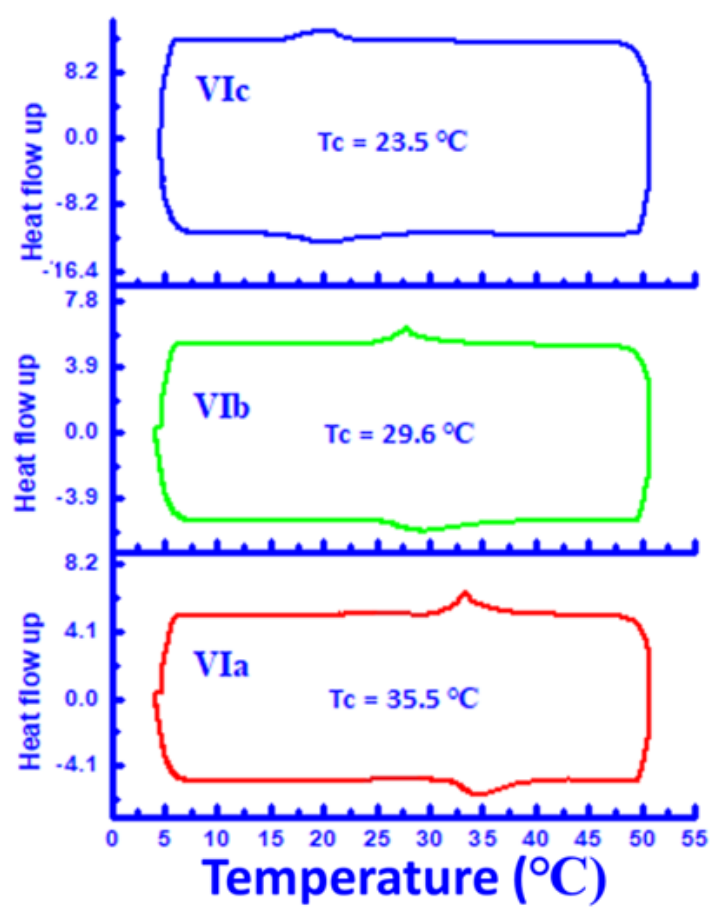

Figure 10

The transition temperature of terpolymers by micro-DSC at the onset point of diffractogram.

Figure 11

A-D: (A-C) the LCST via transmittances vs. temperatures of terpolymers Vla-05, Vlb-10, and Vlc-20 in 0.1-0.5 wt.\% of $\mathrm{Na}_{2} \mathrm{SO}_{4}(\mathrm{~A}), \mathrm{NaCl}(\mathrm{B})$, and $\mathrm{NaSCN}(\mathrm{C})$. (D) summarized the $T_{c^{\prime} s}$ of all terpolymers with variations of salt concentrations.

\section{Supplementary Files}

This is a list of supplementary files associated with this preprint. Click to download.

- GraphicalAbstract.png

- supplement.docx

- Scheme1.png 